\title{
GOLD-ALUMINIUM INTERMETALLIC COMPOUND FORMATION
}

\author{
E. GALLI $\dagger$, G. MAJNI, C. NOBILI, and G. OTTAVIANI \\ Istituto di Fisica, Via Campi 213/A, 41100 Modena, Italy
}

(Received April 11, 1979)

\begin{abstract}
During investigations of failure mechanisms and failure avoidance we have studied the kinetics and the mechanisms responsible for the growth of the $\mathrm{Au}-\mathrm{Al}$ compounds. $\mathrm{Au}_{4} \mathrm{Al}, \mathrm{Au}_{5} \mathrm{Al}_{2}, \mathrm{Au}_{2} \mathrm{Al}, \mathrm{AuAl}, \mathrm{AuAl}_{2}$ have been observed and the growth kinetics of the $\mathrm{Au}_{2} \mathrm{Al}, \mathrm{AuAl}, \mathrm{AuAl}_{2}$ follow a (time) ${ }^{1 / 2}$ dependence. The activation energy for the grow th of $\mathrm{Au}_{2} \mathrm{Al}$ is $1 \mathrm{eV}$ and $1.2 \mathrm{eV}$ was found for $\mathrm{AuAl}$ and $\mathrm{AuAl}_{2}$. The kind of compound formed depends on the samples preparation and the results indicate that the kinetics of the mixing is the main mechanism responsible for the sequence of formation of the various compounds.
\end{abstract}

\section{INTRODUCTION}

$\mathrm{Au}-\mathrm{Al}$ thermocompression bonds are generally used for monolithic and hybrid integrated circuits as well as for discrete devices. Their break-down is caused in most cases by the failure of the Au-Al bonds. Degradation of the bonds appears in their increased resistance or total rupture. It has been observed that in certain cases loose, voided phases appear at the failed $\mathrm{Au}-\mathrm{Al}$ bond, which are described in the literature as $\mathrm{Au}_{\mathrm{m}} \mathrm{Al}_{\mathrm{n}}$ intermetallic phases. ${ }^{1,2,3}$ These phases do not cause failure by themselves but certain types of the failures, i.e. broken metallization around the bond, lifted bonds, cracks are related to the formation of these phases. ${ }^{4,5,6}$

The purpose of the present paper is to show, in the form of an investigation into the failure mechanisms and the possibility of avoidance of them, a) the kinetics of the compound formation and b) the mechanisms responsible for the growth.

\section{EXPERIMENTAL METHOD}

On thermally oxided Si single crystal, $\mathrm{Au}$ and $\mathrm{Al}$ films were deposited in a high vacuum oil-free system by e-gun. To minimize interface effects, mainly due to oxygen contaminations, gold was deposited first followed by Al, without breaking the vacuum. The thicknesses of $\mathrm{Au}$ and $\mathrm{Al}$ range between $1000 \AA$ and $3000 \AA$. Thermal annealing was carried out in a $10^{-7}$ torr furnace in $50^{\circ} \mathrm{C}$ to $500^{\circ} \mathrm{C}$ temperature range. The different compounds were identified by X-ray diffraction and $\mathrm{MeV}^{4} \mathrm{He}^{+}$Rutherford backscattering was used to measure the thicknesses of the compound layers with a resolution of about $200 \AA$. Both the techniques are widely described in the literature. ${ }^{7,8}$

$\dagger$ Istituto di Mineralogia E Petrografia, P. Le S. Eufemia, 2 41100 Modena, Italy.
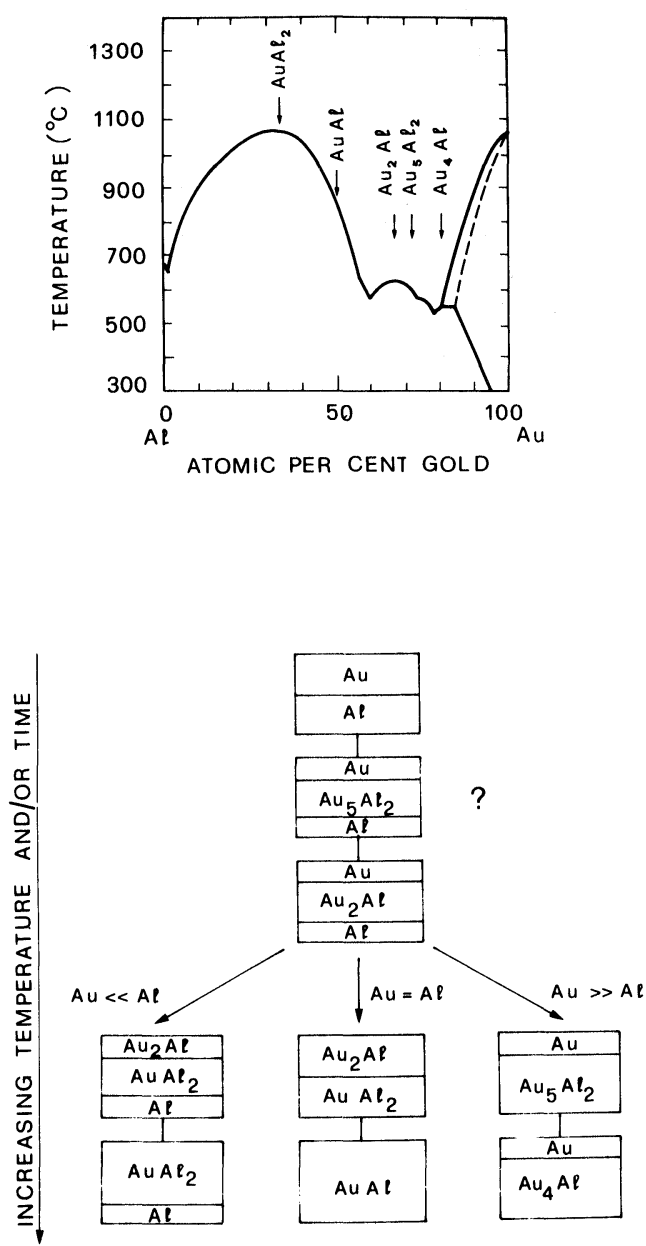

FIGURE 1 Schematic diagrams showing the compound formation in $\mathrm{Au}-\mathrm{Al}$ system. It seems that initially $\mathrm{Au}_{5} \mathrm{Al}_{2}$ is formed by reaction at room temperature. Depending on the relative thickness of $\mathrm{Au}$ and $\mathrm{Al}$ films, different compounds can be formed. 
TABLE I

End phases in the $\mathrm{Au}-\mathrm{Al}$ thin films interactions

\begin{tabular}{lllll}
\hline \multicolumn{2}{l}{$\begin{array}{c}\text { Sample End phase } \\
500^{\circ} \mathrm{C} 10^{\mathrm{h}}\end{array}$} & $\mathrm{Al}$ evaporated & Thickness $(\AA)$ \\
Au evaporated & Compound \\
\hline 1 & $\mathrm{AuAl}_{2}$ & 5700 & 1100 & 3400 \\
2 & $\mathrm{AuAl}_{1}$ & 1400 & 1500 & 3000 \\
3 & $\mathrm{Au}_{2} \mathrm{Al}$ & 850 & 1800 & 2600 \\
4 & $\mathrm{Au}_{5} \mathrm{Al}_{2}$ & 900 & 2500 & 3350 \\
5 & $\mathrm{Au}_{4} \mathrm{Al}$ & 600 & 2400 & 2400 \\
\hline
\end{tabular}

In Figure 1 the phase diagram of the system Au-Al is shown. Five different compounds are predicted: $\mathrm{AuAl}_{2}, \mathrm{AuAl}, \mathrm{Au}_{2} \mathrm{Al}, \mathrm{Au}_{5} \mathrm{Al}_{2}, \mathrm{Au}_{4} \mathrm{Al}$. The sequence of formation for the various compounds is resumed in the same figure. The first phase formed at low temperature is $\mathrm{Au}_{5} \mathrm{Al}_{2}$ in competition with $\mathrm{Au}_{2} \mathrm{Al}$. The question mark near $\mathrm{Au}_{5} \mathrm{Al}_{2}$ indicates that we are not sure if $\mathrm{Au}_{5} \mathrm{Al}_{2}$ is formed before $\mathrm{Au}_{2} \mathrm{Al}$ or not. By pushing the heat treatment $\mathrm{Au}_{2} \mathrm{Al}$ is formed. Now depending upon the relative quantity of $\mathrm{Au}$ and $\mathrm{Al}$ three different sequences can be constructed. The end phases are $\mathrm{AuAl}_{2}$ in the case $\mathrm{Au} \ll \mathrm{Al}, \mathrm{AuAl}$ in the case $\mathrm{Au}=\mathrm{Al}$ and $\mathrm{Au}_{4} \mathrm{Al}$ for $\mathrm{Au} \gg \mathrm{Al}$. These sequences follow a precise scheme: $\mathrm{AuAl}_{2}$ starts to form only when all $\mathrm{Au}$ is consumed, $\mathrm{Au}_{4} \mathrm{Al}$ only when all $\mathrm{Al}$ is consumed and $\mathrm{AuAl}$ starts to develop only when both $\mathrm{Al}$ and $\mathrm{Au}$ are consumed. $\mathrm{Au}_{2} \mathrm{Al}$ and $\mathrm{Au}_{5} \mathrm{Al}_{2}$ are end phases only when the thicknesses of $\mathrm{Au}$ and $\mathrm{Al}$ films were chosen in such a way that the $\mathrm{Au} / \mathrm{Al}$ atomic ratios were made $2 / 1$ and $5 / 2$ respectively. The end phases have been found to be stable up to $500^{\circ} \mathrm{C}$. The list of the samples made is given in Table I, together with thicknesses of $\mathrm{Au}, \mathrm{Al}$ and resulting compound formed after heat treatment. There data have been obtained by a backscattering technique.

The growth rate proportional to $\sqrt{ } \mathrm{t}$ and controlled by a single activation energy $E_{T}$ for different times and temperatures has been determined for $\mathrm{Au}_{2} \mathrm{Al},{ }^{9}$ $\mathrm{AuAl}_{2}$ and $\mathrm{AuAl}$.

Figure 2 shows the typical backscattering spectra of the sample as evaporated and after heat treatment at $247^{\circ} \mathrm{C}$ for different times. The $\mathrm{Au}$ and $\mathrm{Al}$ thicknesses are $1500 \AA$ and $1400 \AA$ respectively. The formation of the compound occurs at room temperature and the high ratio between $\mathrm{Au}$ unreacted and $\mathrm{Au}$ in the compound indicates the presence of $\mathrm{Au}_{5} \mathrm{Al}_{2}$ in agreement with X-ray diffraction analysis. After heat treatment at $247^{\circ} \mathrm{C}$ for 5 min only the compounds $\mathrm{Au}_{2} \mathrm{Al}$ and $\mathrm{AuAl}_{2}$ have been observed as confirmed by X-ray diffraction data. These compounds constitute two layers, not mixed, $\mathrm{Au}_{2} \mathrm{Al}$

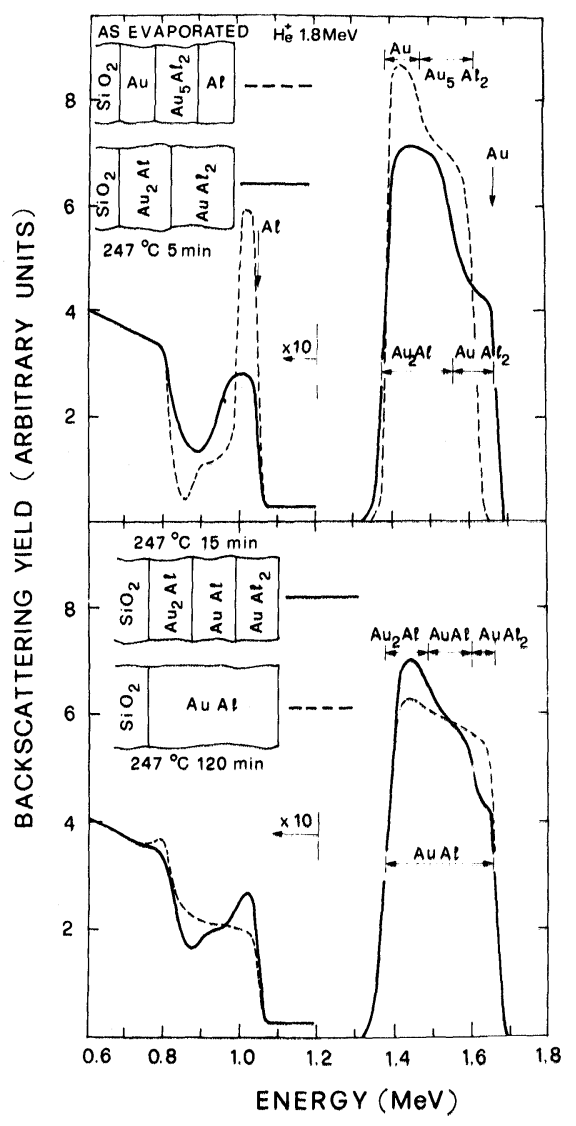

FIGURE $2{ }^{4} \mathrm{He}^{+} \mathrm{MeV}$ backscattering spectra of the samples as evaporated and after annealing at $247^{\circ} \mathrm{C}$ for $5 \mathrm{~min}, 15 \mathrm{~min}$, $120 \mathrm{~min}$.

near the substrate and $\mathrm{AuAl}_{2}$ on top of it. By further heating at the same temperature for $15 \mathrm{~min}$ a step at energies around $1.55 \mathrm{MeV}$ starts to develop. This step corresponds to the formation of a layer of $\mathrm{AuAl}$ between the two previous ones. The AuAl layer grows utilizing material either from $\mathrm{Au}_{2} \mathrm{Al}$ or from $\mathrm{AuAl}_{2}$. $\mathrm{By}$ increasing the annealing time, $\mathrm{AuAl}$ grows and after 120 min $\mathrm{Au}_{2} \mathrm{Al}$ and $\mathrm{AuAl}_{2}$ are almost completely converted into about $3000 \AA$ of $\mathrm{AuAl}$.

Figure 3 reports at two different temperatures, $217^{\circ} \mathrm{C}$ and $247^{\circ} \mathrm{C}$, the dependence of the square of the thicknesses of AuAl upon the annealing time. The experimental data are fitted by a straight line indicating that diffusion through $\mathrm{AuAl}$ is the limiting process for the growth of the compound. The data show the presence of a delay in AuAl formation, a delay which is attributed to the time necessary to consume all the $\mathrm{Al}$ to form $\mathrm{AuAl}_{2}$. Also, in the same figure, the kinetic growth of $\mathrm{AuAl}_{2}$ at $217^{\circ} \mathrm{C}$ 


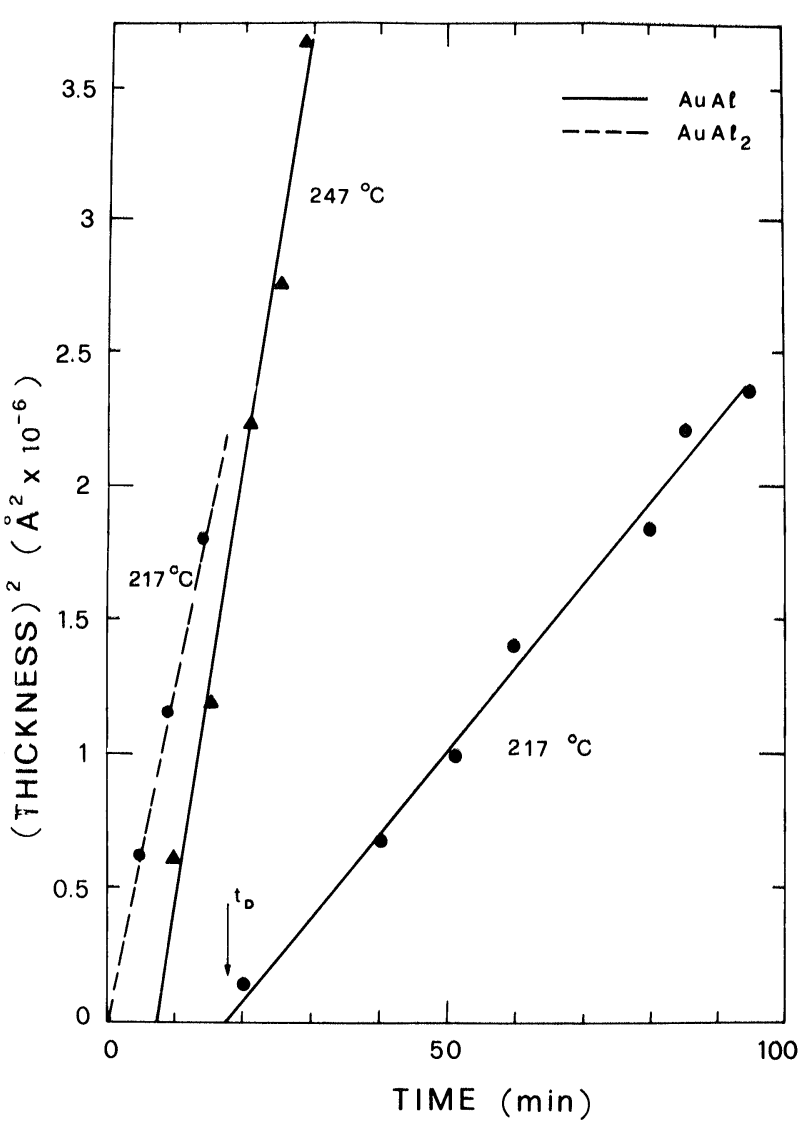

FIGURE 3 Square of $\mathrm{AuAl}$ and $\mathrm{AuAl}_{2}$ thickness as a function of time. $t_{D}$ corresponds to time necessary for the formation of about $1500 \AA$ of $\mathrm{AuAl}_{2}$.

obtained by backscattering data, is reported. This phase has been identified by X-ray diffraction data.

The growth rate of $\mathrm{AuAl}$ and $\mathrm{AuAl}_{2}$ as a function of $1 / T$ is shown in Figure 4 compared with the data obtained for $\mathrm{AuAl}_{2}$ and $\mathrm{Au}_{2} \mathrm{Al}$ compounds by Campisano et al. ${ }^{9}$ AuAl has a growth rate controlled by a single activation energy $E_{T}=1.2 \pm 0.1 \mathrm{eV}$, the same has been obtained from $\mathrm{AuAl}_{2}$. The growth rate of $\mathrm{AuAl}_{2}$ measured here is in agreement with the data of Campisano et al. ${ }^{9}$ The growth rates of $\mathrm{Au}_{4} \mathrm{Al}$ and $\mathrm{Au}_{5} \mathrm{Al}_{2}$ are not measured yet.

Moreover, although quantitative data are not available yet, the impurities play a fundamental role in the kinetics and/or nucleation of intermetallic compound formation. In the $\mathrm{Au}-\mathrm{Al}$ system, for instance, the hydrogen inhibits the phases formation, the presence of $\mathrm{Si}$ accelerates the formation of some phases and the oxygen decomposes the $\mathrm{AuAl}_{2}$ compound.

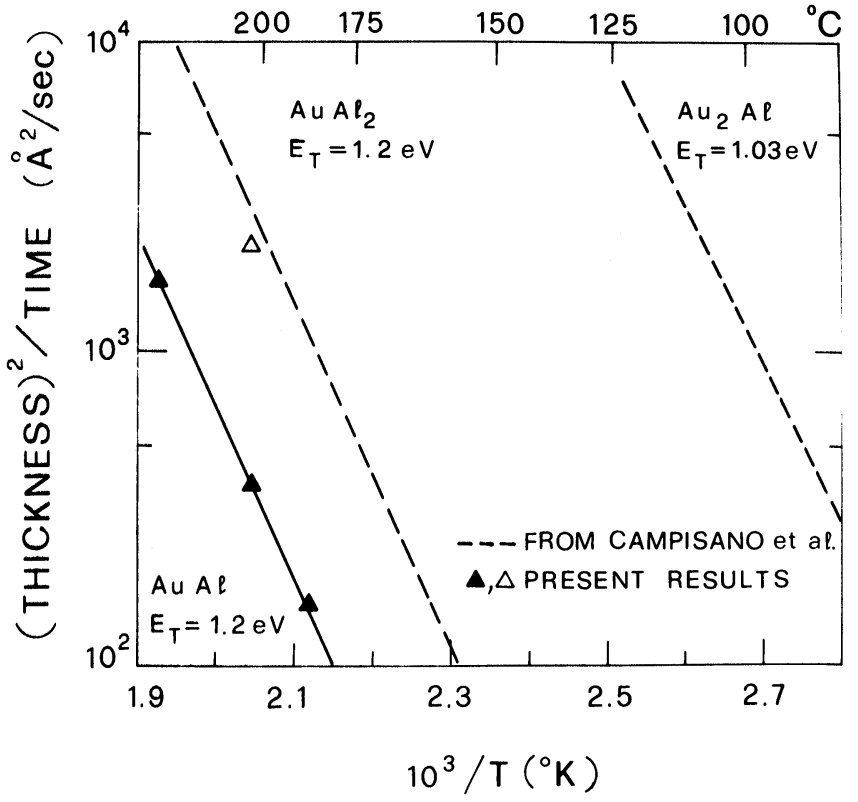

FIGURE 4 Arrhenius plot of $\mathrm{AuAl}, \mathrm{AuAl}_{2}$ and $\mathrm{Au}_{2} \mathrm{Al}$ formation compound.

\section{DISCUSSION AND CONCLUSION}

All the phases predicted by the phase diagram of $\mathrm{Au}-\mathrm{Al}$ system were obtained with a low temperature process by thin film interactions. The sequence and the kind of compounds formed strongly depend upon the thickness of deposited material: samples made differently give different compounds, even if the same heat treatment is performed. This indicates that the kinetics of compound formation and, above all, the end phases, are not controlled by the stability of the compound itself but by the quality and kind of the material available for the reaction. In other words the nucleation of a compound seems to be controlled by the boundary conditions. Also the delay in AuAl formation shown in Figure 3 is due to a nucleation phenomenon inhibited by the presence of $\mathrm{Au}$ or $\mathrm{Al}$ more than to a different growth rate of $\mathrm{AuAl}$ compared to $\mathrm{AuAl}_{2}$ or $\mathrm{Au}_{2} \mathrm{Al}$. The growth kinetic of $\mathrm{Au}_{2} \mathrm{Al},{ }^{9} \mathrm{AuAl}, \mathrm{AuAl}_{2}$ phases is proportional to $\sqrt{ } t$ indicating that the transport across the compound layer is the limiting step in the process. In the temperature range considered one single activation energy $E_{T}$ is found. Marker experiments are necessary in order to identify the moving species.

In conclusion we have shown that the sample preparation plays a fundamental role in the Au-Al phases which are mainly responsible for the failure observed when $\mathrm{Al}$ and $\mathrm{Au}$ are used. 


\section{REFERENCES}

1. E. Philofsky, Solid State Elec 13 (1970) 1391.

2. M. Kashiwabara, and S. Hattori, Rev. Electr. Commun. Lab. 17 (1969) 1001.

3. A. P. Kemény, G. Kalmar and V. Stefaniay, Microelectron. and Reliab. 14 (1975) 499.

4. E. Philofsky, 9th Rel. Phys. Symp. (1971) 114.

5. G. G. Harman, 12th Rel. Phys. Symp. (1974) 131
6. E. Philofsky, and E. L. Hall, IEEE Trans. PHP-11 (1975) 281.

7. J. W. Mayer, and K. N. Tu, J. Vac. Sci. Technol. 11 (1974) 86

8. J. W. Mayer, J. M. Poate and K. N. Tu, Science 190 (1975) 228.

9. S. U. Campisano, G. Foti, E. Rimini, S. S. Lau and J. W. Mayer, Phil. Magazine 31 (1975) 903. 

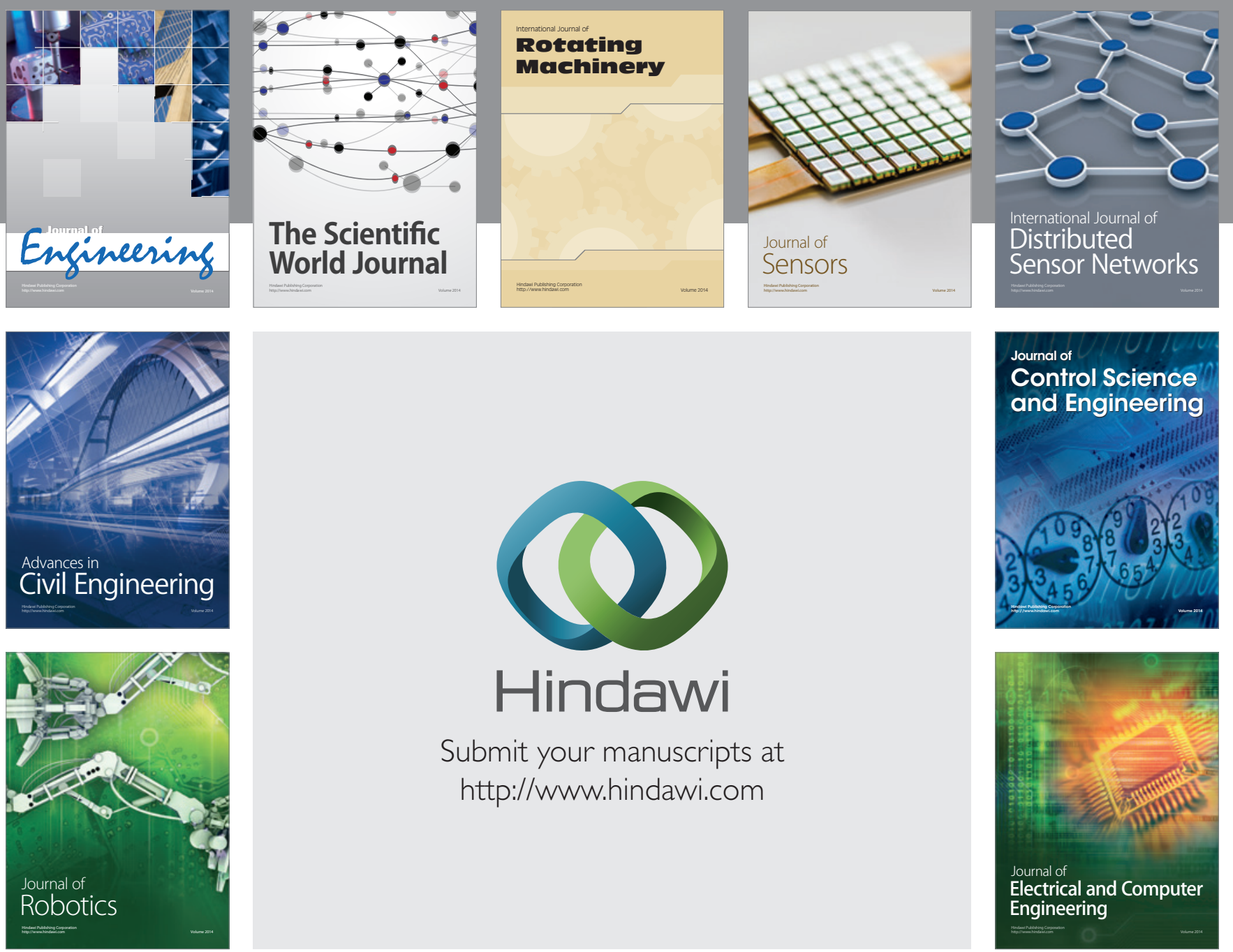

Submit your manuscripts at

http://www.hindawi.com
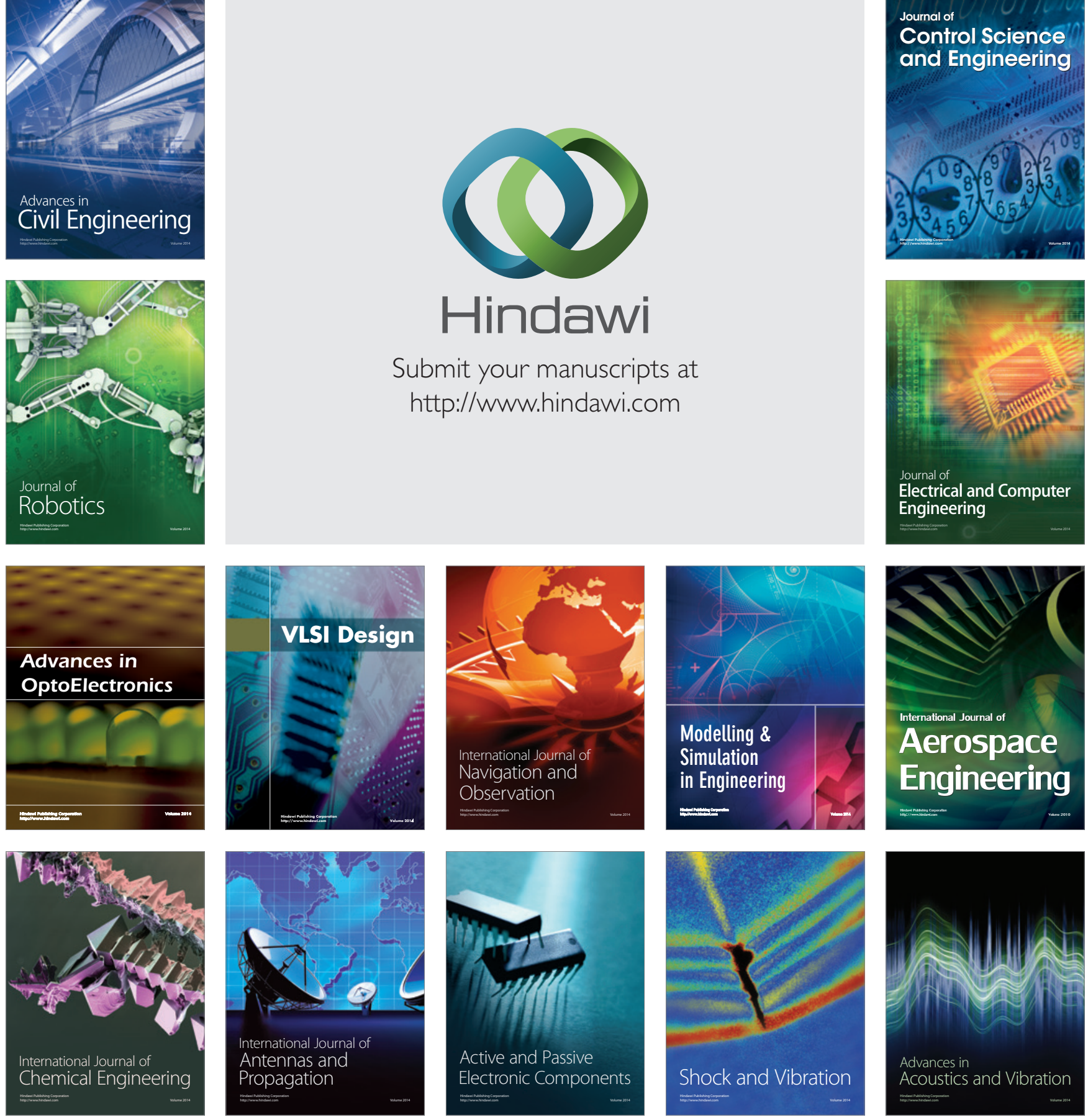